\title{
Experimental and numerical investigation of TVOC concentrations and ventilation dilution in enclosed train cabin
}

\author{
Le Zhao' ${ }^{1}$, Huang Zhou' ${ }^{\text {, Yuzhen } \operatorname{Jin}^{1}(\bowtie) \text {, Zeqing Li }}$ \\ 1. Key Laboratory of Fluid Transmission Technology of Zhejiang Province, Zhejiang Sci-Tech University, Hangzhou 310018, China \\ 2. Hangzhou Yunze Environmental Technology Co., Ltd, Hangzhou, China
}

\begin{abstract}
Air pollution in trains is an important factor threatening human health, which has attracted more and more attention in the worldwide public health researches. In this study, one cabin of a fully enclosed train was taken as an example to conduct experimental and numerical research on pollution level and distribution characteristic of total volatile organic compound (TVOC). The results show that when the average emission rate under daily environmental conditions was taken as the reference, TVOC concentration in the cabin exceeded the limit level of Chinese Indoor Air Quality Standard by more than 4 times. The obvious pollutants accumulative phenomenon could be found at bottoms and corners under the action of airflow. Setting air inlets at the roof of the train, mean age of air ranged from $30 \mathrm{~s}$ to $50 \mathrm{~s}$ in the breathing area. The concentration of pollutants was the lowest at $2.5-5 \mathrm{~m}$ from the center point of the cabin structure, and the ventilation efficiency was the highest. The introduction of clean fresh air could effectively eliminate pollutants. When the complete displacement ventilation rates were $51.4 \mathrm{~h}^{-1}$ and $28.6 \mathrm{~h}^{-1}$, the removal efficiency of pollutants was about 0.85 and $0.48 \mathrm{mg} / \mathrm{m}^{3}$ per minute, respectively. This study was helpful to the improvement and optimization design of air quality and ventilation

mode in trains.
\end{abstract}

\section{Keywords}

indoor air quality;

VOCs;

CFD;

railway cabins;

ventilation dilution

\author{
Article History \\ Received: 17 March 2021 \\ Revised: 03 July 2021 \\ Accepted: 26 July 2021 \\ (c) Tsinghua University Press and \\ Springer-Verlag GmbH Germany, \\ part of Springer Nature 2021
}

\section{Introduction}

Recently, people pay more attention to the existence of volatile organic compounds (VOCs) in cabins of various vehicles. Lv et al. (2020) detected 41 VOCs in 86 Chinese cars. VOCs such as toluene, ethylbenzene and xylene can accumulate in closed cabins and threaten human health (Zhang et al. 2008; Buczynska et al. 2009; Khanchi et al. 2015). For safety, energy saving and thermal comfort, cabins in airplanes, subways and trains all have similar feature of long and narrow structure, high airtightness and big occupant density. These types of interior spaces tend to have higher levels of TVOC pollution and worse air quality. Guan et al. (2014) detected an average of 59 VOCs in 107 flights within a total of 346 VOCs. Guan et al. (2015) conducted continuous measurements in 6 flights and found that the TVOC concentration was approximately $0.4 \mathrm{mg} / \mathrm{m}^{3}$. Li et al. (2006) found a variety of VOCs and particulate pollutants in subways, among which TVOC was 0.3 ppm on average. Gong et al. (2017) measured the level of VOCs pollution in subways and assessed the health risk. Subways running on short distances had more frequent air changes, so the TVOC concentration was lower, about $0.1 \mathrm{mg} / \mathrm{m}^{3}$. Li et al. (2015) found the existence of inherent complexity and uncertainty of the high turbulence in the aircraft cabin which would complicate the diffusion and distribution of pollutants. In order to obtain more accurate measurement data, Li et al. (2014) used the improved sample collection scheme to analyze the distribution characteristics of particles and gaseous pollutants in the aircraft cabin.

Experiment measurements are usually very expensive and time-consuming, and the air samples obtained are usually scarce and unrepresentative of the whole to some extent. Computational fluid dynamics (CFD) method has been widely used recently. Deng and Kim (2007) adopted CFD method to simulate the pollution of VOCs emitted by

E-mail: yzjin@zstu.edu.cn 


\begin{tabular}{|c|c|c|c|}
\hline \multicolumn{4}{|c|}{ List of symbols } \\
\hline$A_{\text {inlet }}$ & air inlets areas $\left(\mathrm{m}^{2}\right)$ & $S c$ & turbulent Schmidt number \\
\hline$A_{\text {outlet }}$ & air outlets areas $\left(\mathrm{m}^{2}\right)$ & $S_{\varphi}$ & source term \\
\hline $\mathrm{ACH}$ & air changes per hour $\left(\mathrm{h}^{-1}\right)$ & TVOC & total volatile organic compound \\
\hline \multirow[t]{2}{*}{$C_{0}$} & initial concentration of TVOC in material & $t$ & time $(\mathrm{s}$ or $\mathrm{h})$ \\
\hline & $\left(\mu \mathrm{g} / \mathrm{m}^{3}\right)$ & $U_{\text {inlet }}$ & inlet air velocities $(\mathrm{m} / \mathrm{s})$ \\
\hline$C_{\mathrm{a}}$ & contaminant concentration in air $\left(\mathrm{mg} / \mathrm{m}^{3}\right)$ & $U_{\text {outlet }}$ & outlet air velocities $(\mathrm{m} / \mathrm{s})$ \\
\hline$C_{\text {inlet }}$ & inflow TVOC concentrations $\left(\mathrm{mg} / \mathrm{m}^{3}\right)$ & $u_{j}$ & air convective velocity $(\mathrm{m} / \mathrm{s})$ \\
\hline$C_{\text {outlet }}$ & outflow TVOC concentrations $\left(\mathrm{mg} / \mathrm{m}^{3}\right)$ & $V$ & volume of the environment cabin $\left(1 \mathrm{~m}^{3}\right)$ \\
\hline CFD & computational fluid dynamics & VOCs & volatile organic compounds \\
\hline $\mathrm{CRH}$ & China railway high-speed & $W$ & time for a complete dilution pollutant (s) \\
\hline$D_{\mathrm{a}}$ & TVOC diffusion coefficient in air $\left(\mathrm{m}^{2} / \mathrm{s}\right)$ & $x$ & one dimensional coordinate $(\mathrm{m})$ \\
\hline$D_{\mathrm{m}}$ & diffusion coefficient $\left(\mathrm{m}^{2} / \mathrm{s}\right)$ & $\Gamma_{\varphi}$ & diffusion coefficient \\
\hline$E(t)$ & emission rate factor $\left(\mu \mathrm{g} /\left(\mathrm{m}^{2} \cdot \mathrm{h}\right)\right)$ & $\delta$ & material thickness $(\mathrm{m})$ \\
\hline f & fresh air ratio $(\%)$ & $\varepsilon_{\mathrm{A}}$ & pollution removal ability of air distribution system \\
\hline IAQ & indoor air quality & $v_{\mathrm{t}}$ & turbulent kinematic viscosity $\left(\mathrm{m}^{2} / \mathrm{s}\right)$ \\
\hline K & partition coefficient between materials and air & $\rho$ & density $\left(\mathrm{kg} / \mathrm{m}^{3}\right)$ \\
\hline Q & ventilation volume $\left(\mathrm{m}^{3} / \mathrm{h}\right)$ & $\tau_{\mathrm{n}}$ & nominal time constant (s) \\
\hline
\end{tabular}

a new carpet, and they suggested turning on the ventilation system for 2 hours before entering the room to eliminate pollutants. Zhang and Zhang (2007) used CFD method to simulate indoor TVOC pollution conditions with different fresh air ratios. Tong and Liu (2020) verified a variety of models in the modeling of VOCs distribution from cabin interior surfaces under solar radiation.

In order to develop a better indoor environment, it is necessary to understand the distribution characteristic of gaseous pollutants which is mainly influenced by the ventilation system and the location of pollution sources ( $\mathrm{Li}$ et al. 2014). Shi et al. (2020) simulated the distribution of ozone and its reactants in airplane cabin with three different ventilation modes. Qin et al. (2020) established a simplified model of a bus cabin with seats as the only emission source of formaldehyde to explore the distribution characteristics, and suggested improving ventilation efficiency at both ends of the cabin. An efficient ventilation system helps to reduce air pollution. Zhu et al. (2010) evaluated the ventilation efficiency of public buses by analyzing the spatial distribution of air velocity and mean age of air. Yang et al. (2018) compared the influence of diffuser types on thermal comfort and pollutant diffusion in trains. Wang et al. (2014b) simulated and evaluated the air distribution systems in three kinds of China railway high-speed $(\mathrm{CRH})$ train cabins. The results indicated that the ventilation efficiency of air distribution system in CRH5 was the highest. The ventilation system of CRH5 was also used in the cabin studied in this work.

The literature for measurements and simulations of air quality inside vehicle cabins has been reviewed. In short,
CFD method has been widely used in a variety of indoor and inboard air quality studies, but there are few studies about pollution measurements and passenger health risk assessments on trains. According to statistics from National Railway Administration of the People's Republic of China, normal trains, which are slower and worse equipped than CHR trains, account for $74 \%$ of total railway mileage by 2020. IAQ of normal trains needs to be taken seriously. The objectives of this work are:

- Develop a suitable simplified three-dimensional CFD model with measured boundary conditions to simulate the airflow and TVOC distribution in the cabin;

- Validate the CFD model by comparing the simulated results with the experimental results;

- Provide scientific data to evaluate the degree of pollution and the ventilation efficiency and provide guidance to optimize air quality in cabins by using the validated CFD model.

\section{Numerical methods}

\subsection{Cabin mock up}

Figure 1 shows a simplified model of one cabin of a normal train to be put into service in China. Decorative materials and unessential structures that are not relevant to this study are ignored, such as metal ornaments and curtains. A large part of both sides of the cabin are closed windows, which do not belong to the emission source of TVOC and are ignored in the model. According to the principle of diagonal 


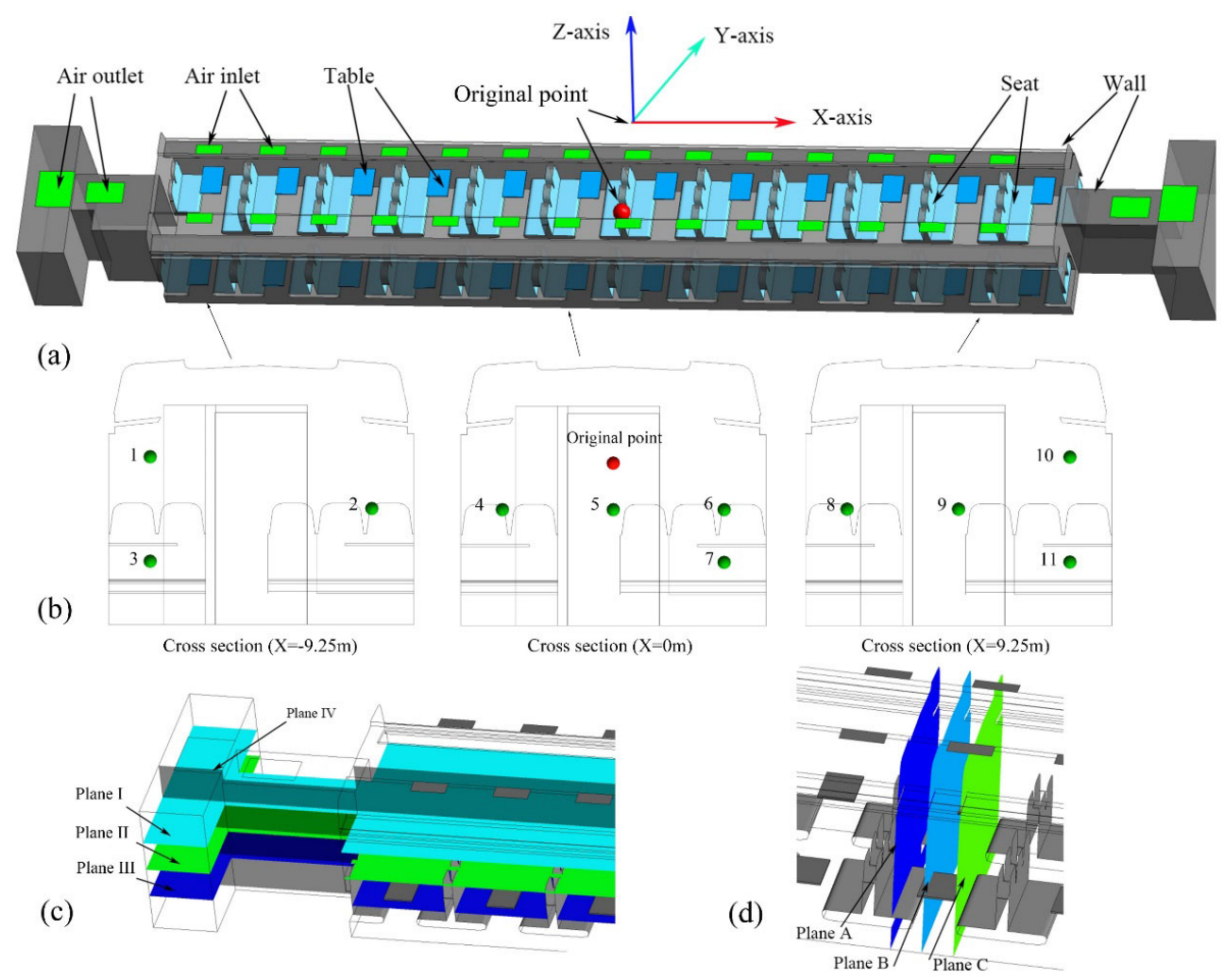

Fig. 1 The computational model of the cabin: (a) structural arrangement and air distribution system; (b) relative location of measuring points; (c) relative position of horizontal sections and longitudinal section: Planes I, II, III, IV; (d) relative position of cross sections: Planes A, B, C

arrangement, 11 measuring points are set up on both sides and in the middle of the cabin. The specific position parameters of measuring points are shown in Table 1. The structural dimensions of the cabin are shown in Table 2 . There are 28 air inlets locating at the top of the train cabin evenly and 4 air outlets locating at both ends of the length. The air distribution system is similar to that used in the CRH5 model. There are 24 rows of seats with 5 seats in each row and two tables between every two rows of seats

Table 1 The specific position parameters of measuring points

\begin{tabular}{cc}
\hline Location & $x, y, z(\mathrm{~m})$ \\
\hline Original point & $0,0,0$ \\
Point 1 & $-9.25,-1.05,0.05$ \\
Point 2 & $-9.25,1.05,-0.45$ \\
Point 3 & $-9.25,-1.05,-0.95$ \\
Point 4 & $0,-1.05,-0.45$ \\
Point 5 & $0,0,-0.45$ \\
Point 6 & $0,1.05,-0.45$ \\
Point 7 & $0,1.05,-0.95$ \\
Point 8 & $9.25,-1.05,-0.45$ \\
Point 9 & $9.25,0,-0.45$ \\
Point 10 & $9.25,1.05,0.05$ \\
Point 11 & $9.25,1.05,-0.95$ \\
\hline
\end{tabular}

Table 2 The structural dimensions of the cabin

\begin{tabular}{cc}
\hline Part & Dimension \\
\hline Length $(\mathrm{m})$ & 25.5 \\
Width $(\mathrm{m})$ & 3.1 \\
Height $(\mathrm{m})$ & 2.5 \\
Roof $\left(\mathrm{m}^{2}\right)$ & 88.4 \\
Floor $\left(\mathrm{m}^{2}\right)$ & 92.0 \\
Table $\left(\mathrm{m}^{2}\right)$ & 5.2 \\
Seat $\left(\mathrm{m}^{2}\right)$ & 60.0 \\
Air inlet $\left(\mathrm{m}^{2}\right)$ & 3.6 \\
Air outlet $\left(\mathrm{m}^{2}\right)$ & 2.0 \\
Cabin volume $\left(\mathrm{m}^{3}\right)$ & 175.0 \\
\hline
\end{tabular}

for a total of 24. The planned number of passengers is 120 . However, the total number can reach 150 considering passengers without seats. In that case, the average usable area is $0.61-0.77 \mathrm{~m}^{2} /$ person.

\subsection{Contaminant emission model}

\subsubsection{Factors affecting VOCs emission from building materials}

The emission behaviors of VOCs from vehicle cabin materials 
can be characterized by three key emission parameters: the initial concentration of TVOC in material $\left(C_{0}, \mu \mathrm{g} / \mathrm{m}^{3}\right)$, the diffusion coefficient $\left(D_{\mathrm{m}}, \mathrm{m}^{2} / \mathrm{s}\right)$, and the partition coefficient ( $K$, dimensionless) (Xiong et al. 2011; Zhang et al. 2016). The VOCs diffusion process in the material is based on Fick's law:

$$
\frac{\partial C_{0}}{\partial t}=D_{\mathrm{m}} \frac{\partial^{2} C_{0}}{\partial x^{2}}
$$

where $t$ is the emission time (s), $x$ is the coordinate in which the VOCs diffusion in the material takes place $(\mathrm{m})$.

Temperature and humidity will change the VOCs emission rate of materials by changing the above three parameters, and the influence of temperature is more significant (Kim et al. 2011; Liu et al. 2014; Wang et al. 2020). Tong and Liu (2020) found that the VOCs pollution level in cars significantly increases under solar radiation. The aim of this work is to estimate the pollution level and distribution of TVOC in the cabin under normal environmental conditions. In order to ignore these two complicated factors, the temperature and relative humidity were fixed at $23{ }^{\circ} \mathrm{C}$ and $50 \%$, respectively in the experimental measurement and numerical simulation. Time is also an important factor that changes the TVOC emission rate of materials. For the VOCs emission of building materials (Xiong et al. 2013), the quasi-steady-state emission rate can be described by the following equation:

$E(t)=2.1 \frac{D_{\mathrm{m}} C_{0}}{\delta} \exp \left(-2.36 \frac{D_{\mathrm{m}} t}{\delta^{2}}\right)$

where $E(t)$ is the emission rate factor $\left(\mu \mathrm{g} /\left(\mathrm{m}^{2} \cdot \mathrm{h}\right)\right) ; \delta$ is the material thickness $(\mathrm{m})$. Thus, it can be seen that the rate of VOCs emitted by materials decreases gradually with time. Generally speaking, with the increase of vehicle age, the VOCs pollution level will be significantly reduced. Chen et al. (2011) found that the total amount of four VOCs detected in a one-year-old bus is five times that of a four-year-old bus. You et al. (2007) measured the TVOC concentration levels of old and new cars, which were $4.9 \mathrm{mg} / \mathrm{m}^{3}$ and $1.2 \mathrm{mg} / \mathrm{m}^{3}$, respectively. It is not practical to measure the concentration of VOCs at regular intervals during the train operation. Therefore, this work takes the train during the initial operation as the research object to estimate the pollution level.

Since the concentration of TVOC in gas phase and solid phase is discontinuous, convection will affect the process of TVOC emitted from the surface of cabin interior surface. The air velocity would change the diffusion coefficient $\left(D_{\mathrm{m}}\right)$ and then change the emission rate (Huang and Haghighat 2002). Deng and Kim (2007) found that there was a small difference in the TVOC emission of a carpet within five days with and without ventilation when the adsorption isotherm was bridged between the air-phase concentration and the solid-phase concentration. Therefore, the concentration jumps at the material-air interface is ignored in order to simplify the model.

\subsubsection{Experimental method of TVOC emission rates}

In short, the TVOC emission rate is a complicated variable, which is not only determined by material and structure, but also affected by the temperature, relative humidity, air velocity and time. It is necessary to measure the TVOC emission rate of typical materials in the cabin.

Gas chromatography (GC) combined with mass spectrometry (MS) is widely used in the analysis of VOCs emitted by materials and human beings, and it is a very mature analytical method (Song et al. 2010; Lv et al. 2020; Zou et al. 2020). Based on the pyrolytic inspiratory chromatography (TD-GC) method, the field measurement of TVOC emission characteristics of four typical building materials in the cabin is carried out in this work. The gas chromatograph (7890A, Agilent, USA) is equipped with a hydrogen flame ionization detector (FID). The environment chamber test system includes temperature and humidity control system, ventilation system, air sample collection device and chemical analysis instrument. The surface area of the tested material sample is $0.5 \mathrm{~m}^{2}$. The environmental chamber (Veous, China) is set in the ventilated mode with an air exchange rate of $0.5 \mathrm{~h}^{-1}$. The temperature and relative humidity in the environment chamber were maintained at $23.0{ }^{\circ} \mathrm{C}$ and $50.0 \%$, respectively. At the beginning of the test, air samples were collected at $12 \mathrm{~h}$ intervals using the Tenax-TA tubes (Markes, UK). The sampling flow was $1.0 \mathrm{~L} / \mathrm{min}$, the sampling time was $20 \mathrm{~min}$, and the sampling volume was $20 \mathrm{~L}$. In the later period of the test, the sampling period was extended to $24 \mathrm{~h}$ due to the slower change of TVOC emission rate. The Tenax-TA tubes were placed in a thermal desorption apparatus (DANI Master TD, Italy) for thermal desorption, and the desorbed gas was injected into GC. In the process of thermal desorption, the temperature of cold trap was $10^{\circ} \mathrm{C}$ and the cooling time was $4 \mathrm{~min}$, the thermal desorption temperature was $280^{\circ} \mathrm{C}$ and the desorption time was $10 \mathrm{~min}$. VOCs in the desorbed gas were separated by a capillary column $(\mathrm{HP}-5,30 \mathrm{~m} \times 320 \mu \mathrm{m} \times 0.25 \mu \mathrm{m})$. The gradient elevated temperature program was to keep $50{ }^{\circ} \mathrm{C}$ for $5 \mathrm{~min}$ at the beginning, then rise to $250{ }^{\circ} \mathrm{C}$ at a rate of $10^{\circ} \mathrm{C} / \mathrm{min}$ and keep for $2 \mathrm{~min}$. With the FID, the airflow rate, the hydrogen flow rate and the tail blowing flow rate were $350 \mathrm{~mL} / \mathrm{min}, 40 \mathrm{~mL} / \mathrm{min}$ and $20 \mathrm{~mL} / \mathrm{min}$, respectively. Pure helium was used as carrier gas with a flow rate of $1.0 \mathrm{~mL} / \mathrm{min}$. 
TVOC standard solutions which contain benzene, toluene, ethylbenzene, m-p-xylene, o-xylene, styrene, butyl acetate, and undecane, were used for identification and quantification of VOCs. Taking the content of each component in the TVOC standard solution as abscissa and the peak area as ordinate, the linear correlation coefficient $R^{2}$ of the standard curve of each component was all greater than 0.99 . The concentrations of other VOCs were calculated as toluene equivalent (Wang et al. 2014a).

The relationship between TVOC concentration in the environmental chamber and the emission amount per unit area detected can be expressed as Eq. (3):

$V \frac{\mathrm{d} C_{\mathrm{a}}}{\mathrm{d} t}=E(t) A-Q C_{\mathrm{a}}$

where $V$ is the volume of the environment chamber $\left(1 \mathrm{~m}^{3}\right)$; $C_{\mathrm{a}}$ is the TVOC concentration in the environment cabin $\left(\mu \mathrm{g} / \mathrm{m}^{3}\right) ; E(t)$ is the TVOC emission rate of the tested material $\left(\mu \mathrm{g} /\left(\mathrm{m}^{2} \cdot \mathrm{h}\right)\right) ; t$ is the emission time $(\mathrm{h}) ; \mathrm{Q}$ is the ventilation volume of the environment cabin $\left(\mathrm{m}^{3} / \mathrm{h}\right)$.

Figure 2 shows the change of TVOC emission rate of PVC floor with time. Based on the least square method and the first-order exponential attenuation model described in Eq. (2), the emission rate $E(t)$ of PVC floor in $\mu \mathrm{g} /\left(\mathrm{m}^{2} \cdot \mathrm{h}\right)$ is as Eq. (4):

$$
E(t)=157.8 \exp (-0.003182 t)
$$

The correlation coefficient $R^{2}$ is 0.94 . Obviously, the TVOC emission rate decreases by an average of $0.22 \%$ per hour. Liu et al. (2021) simulated toluene pollution in painting workshops and compared the approximation between the calculated results and the experimental values when emission sources were constant and non-constant. The results show that non-constant was the most suitable choice, but constant setting did not cause too much deviation. Moreover, time is

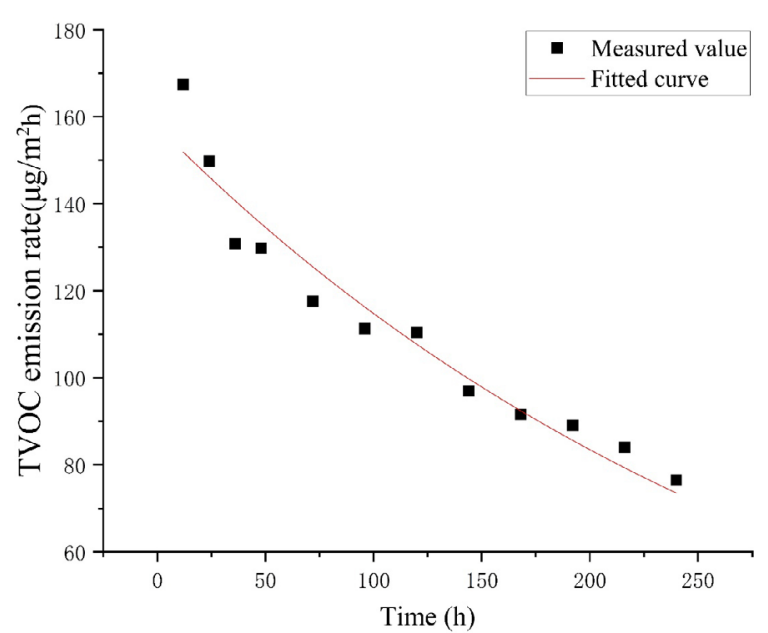

Fig. 2 The change of TVOC emission rate of PVC floor with time not a sensitive factor in the numerical simulation and other experimental measurements, so it is appropriate to take the average value of emission sources as boundary conditions. The average TVOC emission rate of four cabin interior surfaces under daily environmental conditions (temperature: $23{ }^{\circ} \mathrm{C}$, humidity: $50 \%$ ) is shown in Table 3.

Table 3 The average TVOC emission rate of cabin interior surfaces

\begin{tabular}{cccc}
\hline Surface & Roof \& floor & Table & Seat \\
\hline TVOC emission rate $\left(\mu \mathrm{g} /\left(\mathrm{m}^{2} \cdot \mathrm{h}\right)\right)$ & 130.8 & 375.2 & 91.2 \\
\hline
\end{tabular}

\subsection{Boundary conditions and governing equations}

In order to achieve high computational efficiency, we made the following assumptions:

1) The fluid is non-compressible and the pollutants will not react on the airflow.

2) There is no other TVOC source except the roof, floor, tables and seats, and any adsorption effect is ignored.

3) The emission rates of TVOC are uniform and stable.

4) There is no chemical reaction in the simulation and experiment.

As the airflow in the cabin is turbulent, the component transport model and the standard $k-\varepsilon$ turbulence model were used. The standard $k-\varepsilon$ turbulence model is one of the widely used and validated models in the numerical simulation of turbulence (Desai et al. 2021; Gao et al. 2021). The motion of airflow in the cabin is turbulent and is governed by the conservation equations of mass, momentum and energy. These governing equations can be expressed in a general form:

$$
\frac{\partial(\rho \varphi)}{\partial \tau}+\operatorname{div}(\rho u \varphi)=\operatorname{div}\left(\Gamma_{\varphi} \operatorname{grad} \varphi\right)+S_{\varphi}
$$

where $\varphi$ is a universal variable, including $u, v, w, T$, etc.; $\Gamma_{\varphi}$ is the diffusion coefficient; $S_{\varphi}$ is the source term. The transport equations of turbulence energy $(k)$ and its dissipation rate $(\varepsilon)$ are as follows:

$$
\begin{aligned}
\frac{\partial(\rho k)}{\partial t}+\frac{\partial\left(\rho k u_{i}\right)}{\partial x_{i}}= & \frac{\partial}{\partial x_{j}}\left[\left(\mu+\frac{\mu_{\mathrm{t}}}{\sigma_{k}}\right) \frac{\partial k}{\partial x_{j}}\right] \\
& +\mu_{\mathrm{t}}\left(\frac{\partial u_{i}}{\partial x_{j}}+\frac{\partial u_{j}}{\partial x_{i}}\right) \frac{\partial u_{i}}{\partial x_{j}}-\rho \varepsilon \\
\frac{\partial(\rho \varepsilon)}{\partial t}+\frac{\partial\left(\rho \varepsilon u_{i}\right)}{\partial x_{i}}= & \frac{\partial}{\partial x_{j}}\left[\left(\mu+\frac{\mu_{\mathrm{t}}}{\sigma_{\varepsilon}}\right) \frac{\partial \varepsilon}{\partial x_{j}}\right] \\
& +C_{1} \mu_{\mathrm{t}} \frac{\varepsilon}{k}\left(\frac{\partial u_{i}}{\partial x_{j}}+\frac{\partial u_{j}}{\partial x_{i}}\right) \frac{\partial u_{i}}{\partial x_{j}}-C_{2} \rho \frac{\varepsilon^{2}}{k}
\end{aligned}
$$

where the empirical constants $\sigma_{k}, \sigma_{\varepsilon}, C_{1}, C_{2}$ are 1.0, 1.3, 1.44, 
1.92, respectively; $\mu_{\mathrm{t}}$ is the turbulent viscosity. The SIMPLE algorithm was used for the velocity-pressure coupling. The component transport model (Zhang and Zhang 2007) can be described as:

$\frac{\partial C_{\mathrm{a}}}{\partial t}+\frac{\partial}{\partial x_{j}}\left(u_{j} C_{\mathrm{a}}\right)=\frac{\partial}{\partial x_{j}}\left(\left(D_{\mathrm{a}}+\frac{\nu_{\mathrm{t}}}{S c}\right) \frac{\partial C_{\mathrm{a}}}{\partial x_{j}}\right)$

where $C_{\mathrm{a}}$ is the contaminant concentration in air $\left(\mathrm{mg} / \mathrm{m}^{3}\right)$; $D_{\mathrm{a}}$ is the TVOC diffusion coefficient in air $\left(6 \times 10^{-5} \mathrm{~m}^{2} / \mathrm{s}\right) ; v_{\mathrm{t}}$ is the turbulent kinematic viscosity $\left(\mathrm{m}^{2} / \mathrm{s}\right) ; \mathrm{Sc}$ is the turbulent Schmidt number and $u_{j}$ is the air convective velocity $(\mathrm{m} / \mathrm{s})$.

The boundary conditions used in the simulation are shown in Table 4. For different air inlet velocities, three cases were simulated and compared. Changing the air velocity from $0.1 \mathrm{~m} / \mathrm{s}$ to $0.7 \mathrm{~m} / \mathrm{s}$ (You et al. 2007), TVOC concentration level in cars decreased from $1.8 \mathrm{mg} / \mathrm{m}^{3}$ to $1.2 \mathrm{mg} / \mathrm{m}^{3}$ accordingly. Increasing the air velocity means increasing the TVOC transport driving force and the fresh air volume, which together result in the removal of pollutants. In the three cases, circulating air without fresh air is used to investigate the effect of air inlet velocities on pollutants distributions. For recirculated ventilation, the inlet concentration depends on the outlet concentration and the fresh air ratio. Based on mass conservation, the relationship between import and export boundary conditions can be described as:

$C_{\text {inlet }} A_{\text {inlet }} U_{\text {inlet }}=(1-f) C_{\text {outlet }} A_{\text {outlet }} U_{\text {outlet }}$

where $U_{\text {inlet }}$ and $U_{\text {outlet }}$ are the inlet and outlet air velocities $(\mathrm{m} / \mathrm{s})$, respectively; $C_{\text {inlet }}$ and $C_{\text {outlet }}$ are the inflow and outflow TVOC concentrations $\left(\mathrm{mg} / \mathrm{m}^{3}\right)$, respectively; $f$ is the fresh air ratio; $A_{\text {inlet }}$ and $A_{\text {outlet }}$ are the air inlets and outlets areas $\left(\mathrm{m}^{2}\right)$, respectively.

In this study, the mean age of air (Kato and Murakami 1988; Li et al. 2003) is used as an indicator to evaluate the ventilation efficiency in the cabin. The mean age of air is defined as the mean time it took for the air from the supply openings to be transported at a specified location. The mean

Table 4 Boundary conditions of CFD simulation

\begin{tabular}{cc}
\hline & $\begin{array}{c}\text { Velocity-inlet, turbulence intensity: } 5.0 \% \\
\text { Temperature: } 288.0 \mathrm{~K}\end{array}$ \\
\cline { 2 - 2 } Air inlet & $\begin{array}{c}\text { Case I: velocity: } 0.2 \mathrm{~m} / \mathrm{s} \text {, airflow rate: } 0.70 \mathrm{~m}^{3} / \mathrm{s} \\
\text { Case II: velocity: } 0.4 \mathrm{~m} / \mathrm{s} \text {, airflow rate: } 1.39 \mathrm{~m}^{3} / \mathrm{s} \\
\text { Case III: velocity: } 0.7 \mathrm{~m} / \mathrm{s} \text {, airflow rate: } 2.43 \mathrm{~m}^{3} / \mathrm{s}\end{array}$ \\
\hline Air outlet & Pressure-outlet, free slip \\
Roof \& floor & Constant mass-flow-inlet: $3.63 \mathrm{e}-11 \mathrm{~kg} /\left(\mathrm{m}^{2} \cdot \mathrm{s}\right)$ \\
Table & Constant mass-flow-inlet: $10.42 \mathrm{e}-11 \mathrm{~kg} /\left(\mathrm{m}^{2} \cdot \mathrm{s}\right)$ \\
Seat & Constant mass-flow-inlet: $2.53 \mathrm{e}-11 \mathrm{~kg} /\left(\mathrm{m}^{2} \cdot \mathrm{s}\right)$ \\
Wall & No-slip, standard adiabatic wall function
\end{tabular}

age of air can be described as the following equation:

$$
\begin{aligned}
& \frac{\partial}{\partial x}(u \tau)+\frac{\partial}{\partial y}(v \tau)+\frac{\partial}{\partial z}(w \tau) \\
& =\frac{\partial}{\partial x}\left(\Gamma_{\tau} \frac{\partial \tau}{\partial x}\right)+\frac{\partial}{\partial y}\left(\Gamma_{\tau} \frac{\partial \tau}{\partial y}\right)+\frac{\partial}{\partial z}\left(\Gamma_{\tau} \frac{\partial \tau}{\partial z}\right)+1
\end{aligned}
$$

where $u, v$ and $w$ are the velocities in the directions of $x, y$ and $z$ axes, respectively; $\Gamma_{\tau}$ is the diffusion coefficient. The transport equation is written as a user-defined function (UDF) using $\mathrm{C}$ language, and imported into Fluent for calculation.

\subsection{CFD Model validation and discussion}

\subsubsection{Mesh independence study}

An appropriate mesh is essential for a precise CFD model. When the results become mesh-independent, a further increase in the mesh number could not effectively improve the simulation accuracy but instead brings an extra computational cost, thus is unnecessary. To find out the most effective grid resolution for our simulation, the cabin model is meshed with five mesh numbers, as shown in Table 5 . A $2 \mathrm{~m}$ line segment (breathing level) on the $Y$-axis in the middle of the cabin is selected as the monitoring line, and 20 evenly distributed monitoring points are selected on this line segment to examine the ventilation and pollutant distribution. The variation of the average flow velocity at the monitoring points for different mesh group is shown in Table 5. When the number of meshes is increased from 2482640 to 3113908 , the change in the flow velocity is thousandth. As shown in Figure 3, the increase of mesh number has little effect on the distribution of TVOC concentration. Therefore, it can be concluded that a mesh number between 2.5 million and 3.0 million is appropriate for our considered problem. After the local mesh is encrypted, the mesh number is finally determined to be 2.84 million. Figure 4 shows the generated mesh for the simulation, which is same on the $X$-axis. The seating area we are more interested in are meshed with structural grids, while the aisle of the cabin is meshed with unstructured grids.

Table 5 The grid independence test of mean flow velocity at 20 monitoring points on the reference line

\begin{tabular}{ccc}
\hline Type & Cell number & Mean flow velocity $(\mathrm{m} / \mathrm{s})$ \\
\hline Grid 1 & 1063891 & 0.102763 \\
Grid 2 & 1354642 & 0.104173 \\
Grid 3 & 1848339 & 0.105556 \\
Grid 4 & 2482640 & 0.111345 \\
Grid 5 & 3113908 & 0.112554 \\
\hline
\end{tabular}




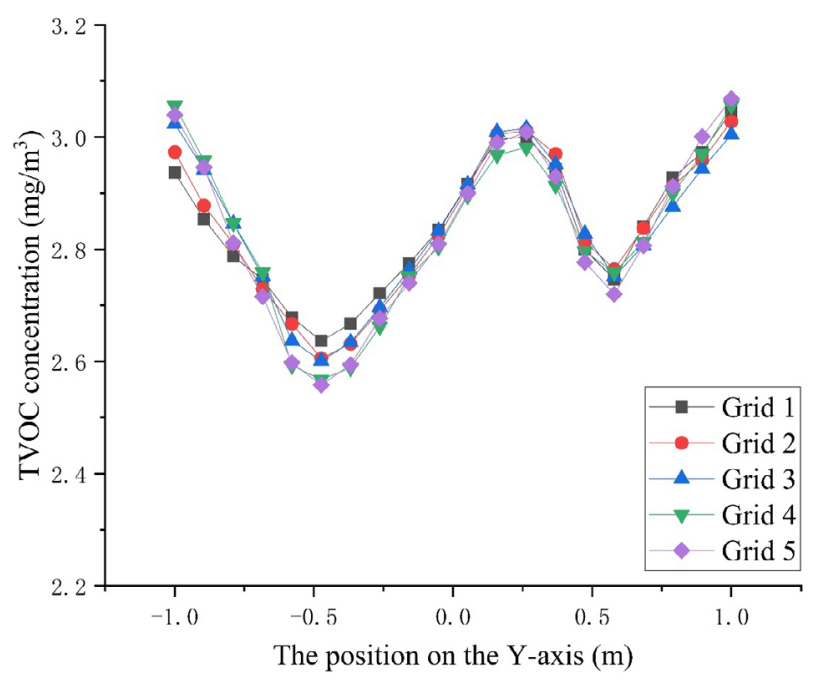

Fig. 3 TVOC concentration at 20 monitoring points on the reference line with different grid numbers

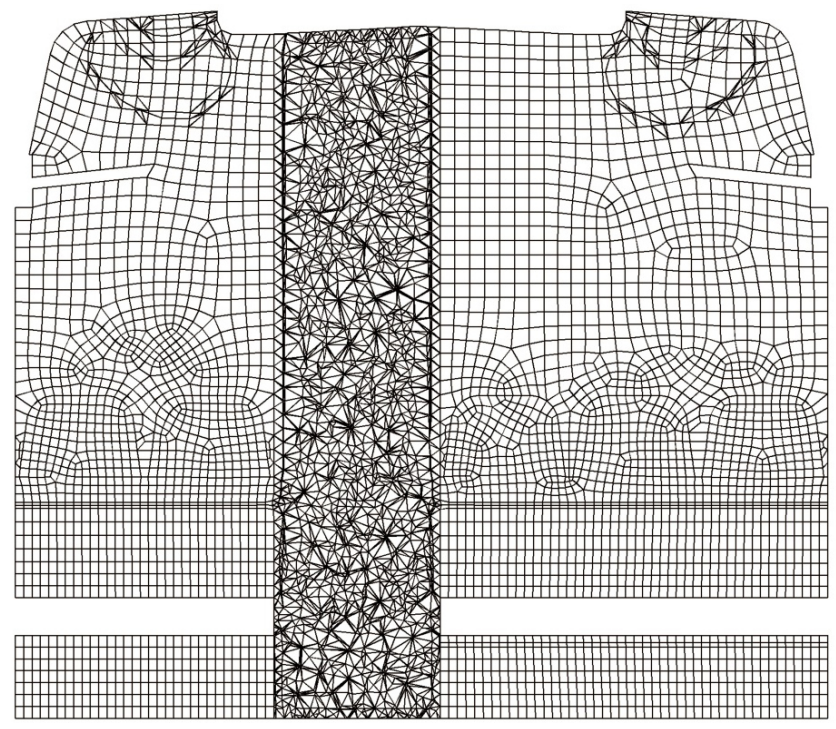

Fig. 4 The generated mesh for the simulation

\subsubsection{The comparison of experimental and simulation results}

The verification of the CFD model was divided into two parts. The first part was to investigate the accuracy of the boundary conditions, e.g., the TVOC emission rates at various interior surfaces. A static condition was considered in the experiment and simulation in this part by assuming that there was no circulating air in the cabin. Figure 5 shows the actual measurement of the variation of the average TVOC concentration in the cabin with resting time under daily environmental conditions. As can be seen from Figure 5, estimating the whole from 11 measuring points, the pollution contribution rate of all interior surfaces was approximately $0.22 \mathrm{mg} / \mathrm{m}^{3} \cdot \mathrm{h}$ in fact. Based on the TVOC emission rates given in Table 3 , and assuming that pollutant distribution

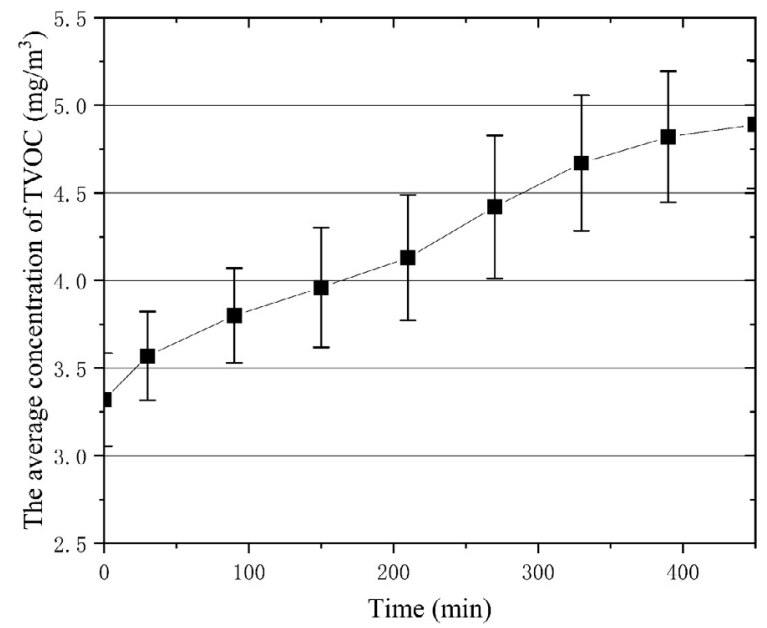

Fig. 5 The average concentration of TVOC changes with the cabin resting time

was uniform, the average pollutant generation rate in the cabin was $0.18 \mathrm{mg} /\left(\mathrm{m}^{3} \cdot \mathrm{h}\right)$. The uneven distribution of pollutants in actual cabin was the reason for discrepancy between the experiment and simulation results. As shown in Figure 6, without the circulating air, the distribution of TVOC in the carriage was uneven and an obvious concentration gradient can be observed. Since the TVOC contained a variety of substances, toluene was taken as the representative substance in the numerical simulation, with a relative molecular weight of 92.14 and a density of $0.866 \mathrm{~g} / \mathrm{cm}^{3}$ at room temperature.

The second part was to verify the accuracy of the selected model and algorithm. Both the experiment and the simulation in this part of the verification were treated as unsteady by taking into consideration the circulating air in the cabin. After several times of complete fresh air cleaning, the physical car was left to rest for $12 \mathrm{~h}$ under normal environmental conditions $\left(18-25^{\circ} \mathrm{C}\right)$. Then the circulation ventilation without fresh air ran, the airflow rate was $2.43 \mathrm{~m}^{3} / \mathrm{s}$ at the inlet and the temperature of air conditioning system was $23^{\circ} \mathrm{C}$. Finally,

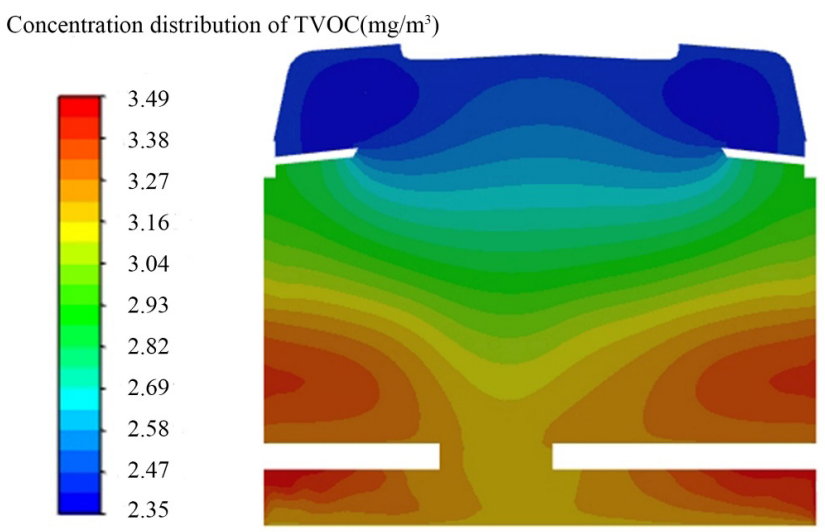

Fig. 6 TVOC concentration distribution without circulating air at Plane A after standing for $12 \mathrm{~h}$ 
the air samples were extracted by conductive silicone tubes $(4 \mathrm{~mm} \times 6 \mathrm{~mm})$ and the air pump, according to the locations of measuring points in Figure 1. Tenax-TA adsorption tubes were uniformly used to collect interior air and the ppbRAE 3000 (PGM-7340, RAE Systems Inc, USA) was used to test the background TVOC concentration. Then, the experimental values were obtained. Similarly, the circulating ventilation was turned on after standing for 12 hours in the CFD simulation. When the concentration values at the 11 measuring points were stable, the simulation values were obtained. Figure 7 shows the comparison of simulated and experimental values at 11 measuring positions. Because a small number of other sources of TVOC emissions, such as adhesives and paints, were ignored in the simulation, the experimental values were generally higher than the simulation values. The mean relative error between the simulation and experimental values was $6.86 \%$, which shows a reasonable agreement.

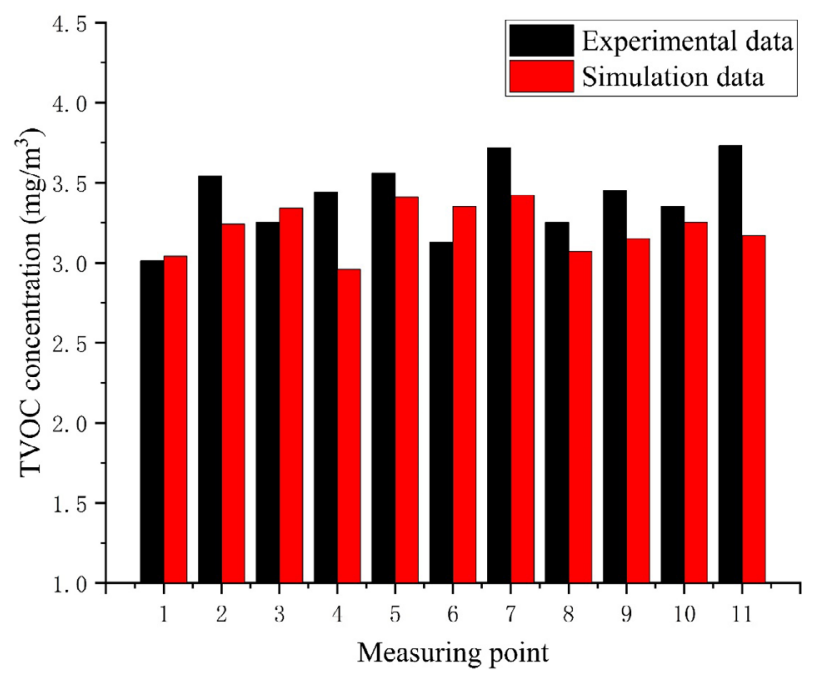

Fig. 7 The comparison of simulation and experimental values at 11 measuring positions

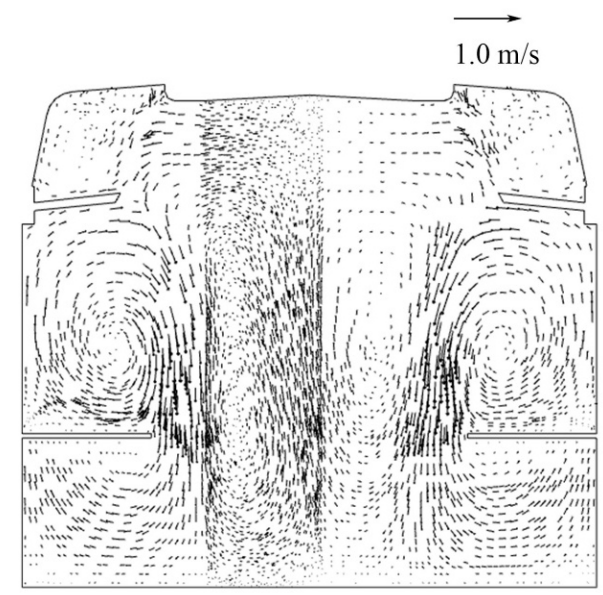

Plane B

\section{Results and discussions}

\subsection{The air velocity distribution under circulating ventilation}

Figure 8 shows the airflow field. Planes B and C correspond to cross sections of indirect and direct air inlets respectively (see Figure 1). Due to the difference of seats on both sides, the cabin has no symmetry. It also breaks the symmetry of the airflow from those evenly distributed air inlets. The district of three seats has more space for airflow than the district of two seats. Four eddies of varying intensity along the width of the cabin can be observed. The eddies in Plane $\mathrm{C}$ are obviously stronger than those in Plane $\mathrm{B}$. These eddies are limited to the surfaces of seats, tables and walls. The eddy strength is weaker at the top and bottom corners due to the obstruction of luggage racks and seats. The movement of air affects the diffusion process and distribution characteristics of TVOC.

\subsection{TVOC concentration distribution}

Figure 9 shows the concentration distribution of TVOC. The black rectangle represents the breathing area in all figures. Cross sections at different locations in the three cases are compared. Only the initial velocities of circulating air (without fresh air) are different in the three cases. Contrasting to the analysis of the velocity vector distribution in previous section, the simulation results show that the TVOC tends to accumulate in areas where the flow motion is weak. The TVOC comes from the circulating air and the emission of cabin interior surfaces. Contaminants are squeezed into the right angles formed between tables or seats and walls by eddies, creating localized areas of high concentration. The average TVOC concentration decreases when the cross sections approach the air inlets. Although increasing the

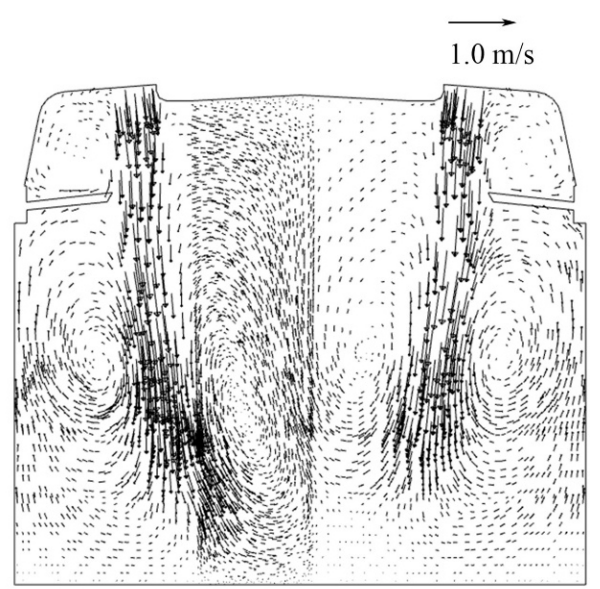

Plane C

Fig. 8 Airflow field 


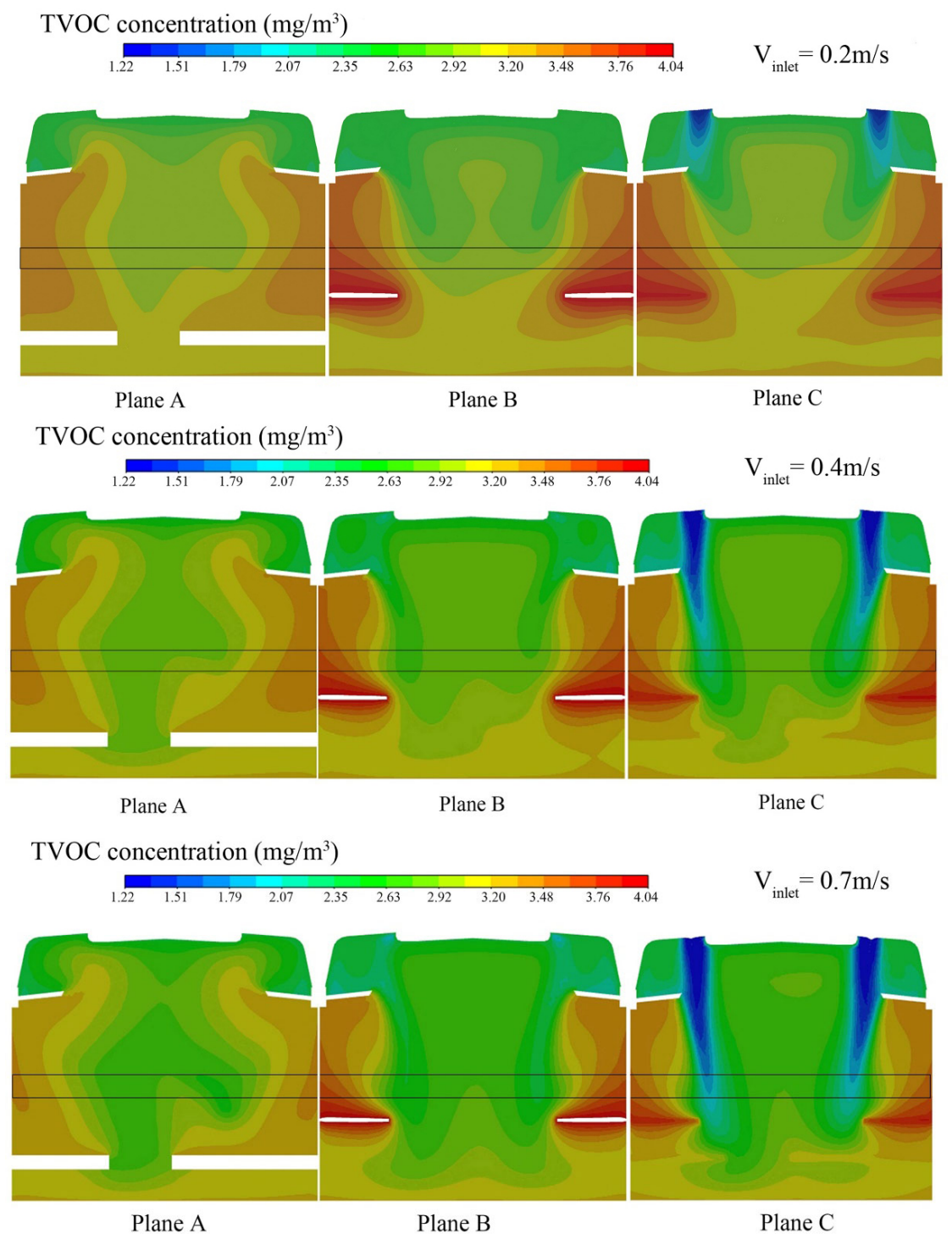

Fig. 9 TVOC concentration distributions in three cases

flow velocity will not change the distribution of TVOC in the cabin significantly, it will make pollutants accumulate at the bottom in different degrees, thus improves the air quality of breathing area.

The TVOC emission rates of the roof and floor are the same in our CFD simulations. However, because of the action of airflow, the TVOC concentration near the floor is $0.5 \mathrm{mg} / \mathrm{m}^{3}$ higher than that near the roof, accounting for $14.3 \%$ of the overall average concentration. In the CFD simulation, the emission rate of the tables is the largest, which is about 3 times that of the roof (floor), so the contaminants emitted by the tables account for the largest proportion overall.

There are high concentration areas near walls on both sides of the cabin width. On the one hand, the phenomenon is caused by eddies of airflow. On the other hand, it may due to that the tables with the highest emission rate are closer to the walls. We appropriately reduced the release rate of the tray table to further investigate the main reasons for such phenomenon. Figure 10 shows the TVOC concentration distribution after reducing the emission rate of tables. The concentrations of contaminants in the aisle shown in Planes $\mathrm{B}$ and $\mathrm{C}$ are significantly higher than that in the seating area. It can be found from the air velocity vector distribution shown in Figure 8 that the flow motion attempts to carry pollutants from the bottom to the top, while changes in concentration gradients also show this trend. The high concentration area near the walls disappears and there is a significant concentration of contaminants in the bottom of the cabin. This shows that airflow only plays a marginal role in the distribution of pollutants, and more importantly, the intensity and location of emission sources.

People are more concerned about TVOC pollution in the breathing area. Figure 11 shows the concentration 


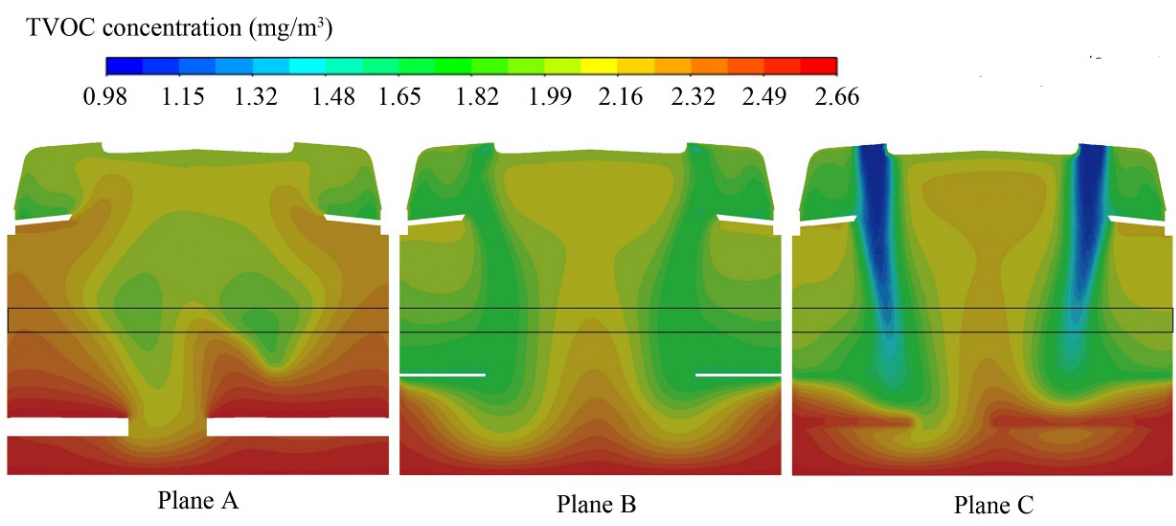

Fig. 10 TVOC concentration distributions after reducing the emission rate of tables

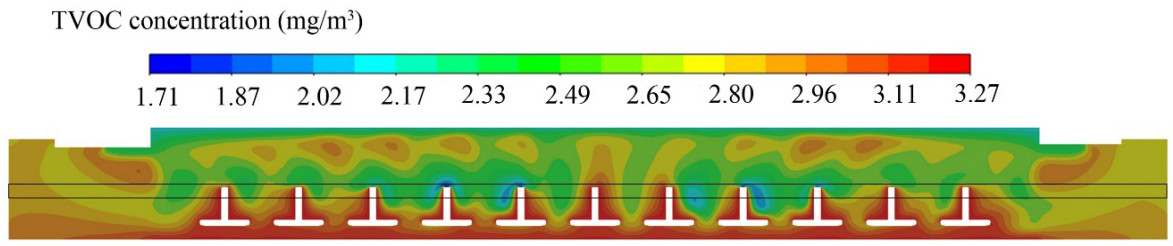

Fig. 11 TVOC concentration distributions at Plane IV

distribution of TVOC in Plane IV. Turning on the recirculated ventilation, the TVOC concentration in the breathing area decreases from $3.06-3.31 \mathrm{mg} / \mathrm{m}^{3}$ to $2.08-2.45 \mathrm{mg} / \mathrm{m}^{3}$ due to the airflow. In addition, most of the contaminants are concentrated below the breathing height and under the seat. However, the average TVOC concentration is still 4-6 times higher than the allowable value $\left(0.6 \mathrm{mg} / \mathrm{m}^{3}\right)$.

Since the change of wind speed has little effect on the distribution of pollutants, only case III is discussed. Figure 12 shows the TVOC concentration distributions on the horizontal sections at different heights. As the circulating air flows from top to bottom, the kinetic energy of air and the driving force of pollutants transportation decreases gradually. The TVOC concentration gradient is obvious on Plane I which is closest to the air inlets at the roof. Horizontal-sectional average TVOC concentration increases gradually as the height decreases. Pollutant concentration is higher at edges of the cabin where the circulating air is difficult to reach.

In the center of the car, there is a small section $\mathrm{X}$ where TVOC concentration is higher. This phenomenon is more evident in Figure 11. The central point of the cabin structure is also the point of symmetry for the airflow. Symmetrical airflow pattern brings this localized section a high concentration.

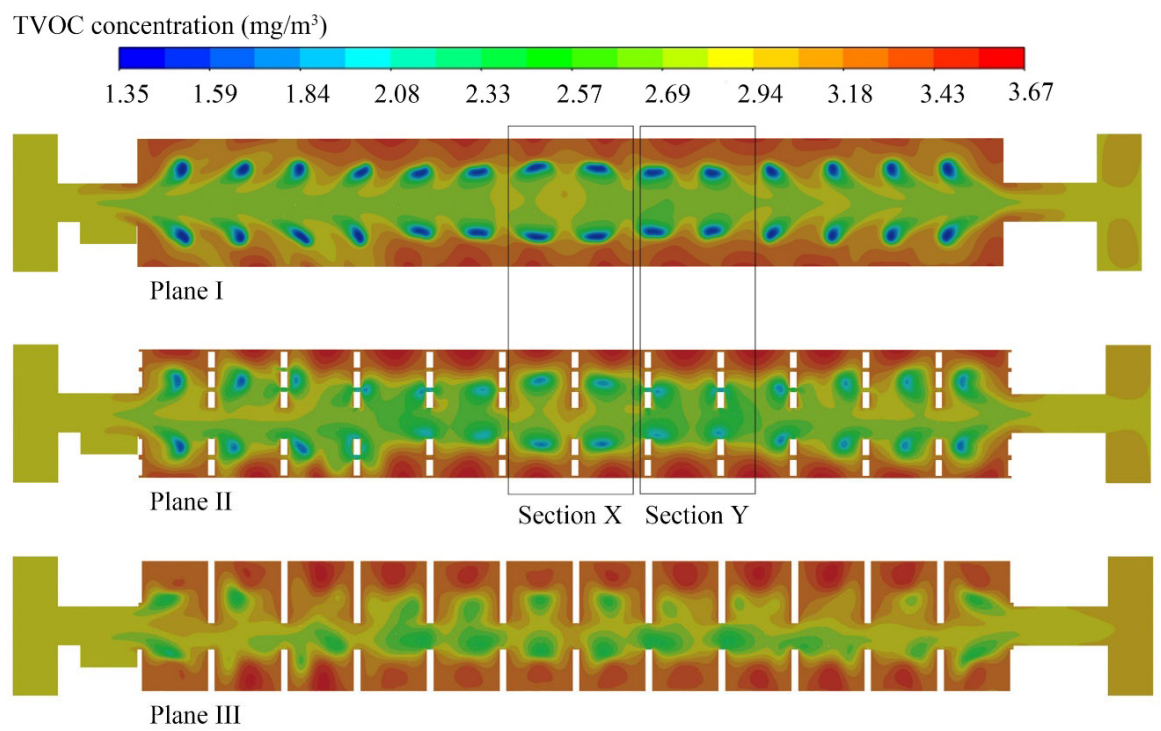

Fig. 12 TVOC concentration distributions at different heights on horizontal section 
There is a small section $\mathrm{Y}$ where the TVOC concentration is lower. Pollutants in section $\mathrm{Y}$ are partly carried by the airflow and diffuse to the air outlets, and partly diffuse to section $\mathrm{X}$. Therefore, there will be locations near this position with the lowest TVOC concentration. Figure 13 shows the distribution of TVOC concentrations at different heights on longitudinal section. The distribution characteristics about the center point of the cabin mechanism are symmetric. Pollutants tend to accumulate towards the air outlets with airflow. The pollutants concentrations are higher at the regions closer to the air outlets. The TVOC concentration fluctuates at the same height. Positions of the maximal correspond to positions of Plane $\mathrm{B}$, while positions of the minimal correspond to positions of Plane C. The overall pollutant degree is lower at the breathing level.

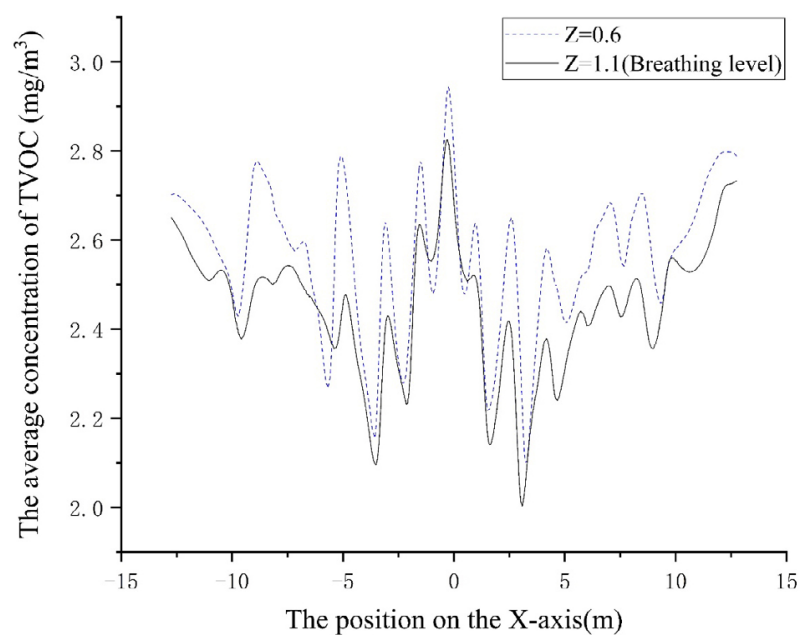

Fig. 13 TVOC concentrations distribution at different heights on longitudinal section

\subsection{The mean age of air}

Figure 14 shows the distribution of the mean age of air at three different planes in the cabin. The circulating airflow rate at the inlet is $2.43 \mathrm{~m}^{3} / \mathrm{s}$ and the air exchange rate is $51.4 \mathrm{~h}^{-1}$. The mean age of air in the breathing area is $20-40 \mathrm{~s}$. The average time of air arrival is longer in the middle position at roof of the cabin and corners of luggage rack, and mean age of air mainly ranges of 50-70 s.

Gradient changes in the mean age of air represent the path of airflow, as shown by the black arrow on Plane $\mathrm{C}$ in Figure 14. Air comes from the air inlets at the roof and moves from top to bottom, with a small horizontal velocity component. After arriving the surfaces of seats and tables, the air begins to spread out and split into two parts. One part of the air diffuses towards the bottom corners of the cabin. Another part of the air moves from bottom to top. Therefore, the mean age of air in the middle of two air inlets is inversely proportional to height. Therefore, the order in which air moves is: the breathing area, edge of width, bottom corners, top space. The top air supply allows the air to reach the breathing area first, where the average air age is minimum, that is, the ventilation efficiency is highest. It can be predicted that air may not be able to reach the breathing area directly due to the obstruction of seats and tables if it is supplied from bottom. If the top side air supply mode is used, because of the small vertical velocity component, air will reach the edge of the car width first. Both of these methods will increase the mean age of air in the breathing area and reduce the ventilation efficiency. It may be possible to supply air from both sides, close to the breathing area. However, the closer air inlets are to the breathing area, the more obvious thermal comfort problem will be. At the same time, whether this method can better control pollutants outside the breathing area is also a problem worth studying.

Zhu et al. (2010) found that the mean age of air of a school bus was between 35 and $120 \mathrm{~s}$, and believed that the pollutants inside the bus could be completely eliminated within 2 minutes under the action of whole fresh air. It is not accurate to draw conclusions from this point of view alone. Because pollutants from areas with high dilution efficiency will be carried to areas with low dilution efficiency by airflow. This will take longer than expected for all pollutants to be exhausted. Wang et al. (2014b) found that when the mean age of air was $94 \mathrm{~s}$ in the CRH5, it took $153 \mathrm{~s}$ to eliminate $90 \%$ cough droplet. Using $\varepsilon_{\mathrm{A}}$ which could reflect the pollution removal ability of air distribution system, as an

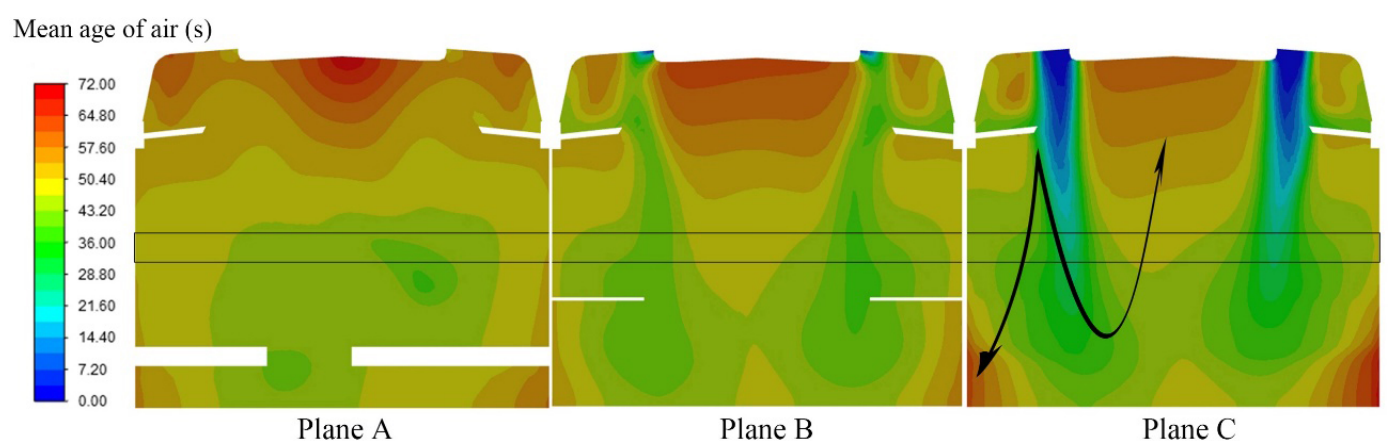

Fig. 14 Distribution of mean age of air 
index to evaluate ventilation efficiency is appropriate (Nielsen 2009; Wang et al. 2014b). The index $\varepsilon_{\mathrm{A}}$ can be determined by Eq. (11):

$\varepsilon_{\mathrm{A}}=\tau_{\mathrm{n}} / W$

where $W$ is the time that all pollutants are exhausted; $\tau_{\mathrm{n}}$ is nominal time constant.

The time $(W)$ required for all pollutants (cough droplet) to be exhausted is minimal in the CRH5, that is, the value of $\varepsilon_{\mathrm{A}}$ is maximum (Wang et al. 2014b). However, considering there are great differences in physical and chemical properties between cough droplet and gaseous pollutants, it is limited to study only the removal ability of cough droplet in the cabin. The TVOC removal ability of air distribution system in the cabin is described in the next section. We have calculated the theoretical time $(W)$ for complete removal of TVOC under displacement ventilation conditions.

Figure 15 shows the air age distribution at different heights in the direction of cabin passage length. Due to staggered placement of air inlets, the mean age of air fluctuates in the horizontal direction. In Figure 15, positions of the maximal value correspond to positions of Plane $\mathrm{B}$, while positions of the minimal value correspond to positions of Plane $C$. The mean air age at height of $1.1 \mathrm{~m}$ is greater than that at height of $0.6 \mathrm{~m}$, that is to say, the ventilation efficiency is inversely proportional to height. This is contrary to the conclusion in Figure 13. This means the path of air movement is bottom to top. Note that there is no direct correlation between ventilation efficiency and pollution degree for circulating ventilation. The increase of average gas age means that the kinetic energy of airflow decreases gradually, the driving force of component transport decreases, and the influence of airflow on pollutant distribution decreases.

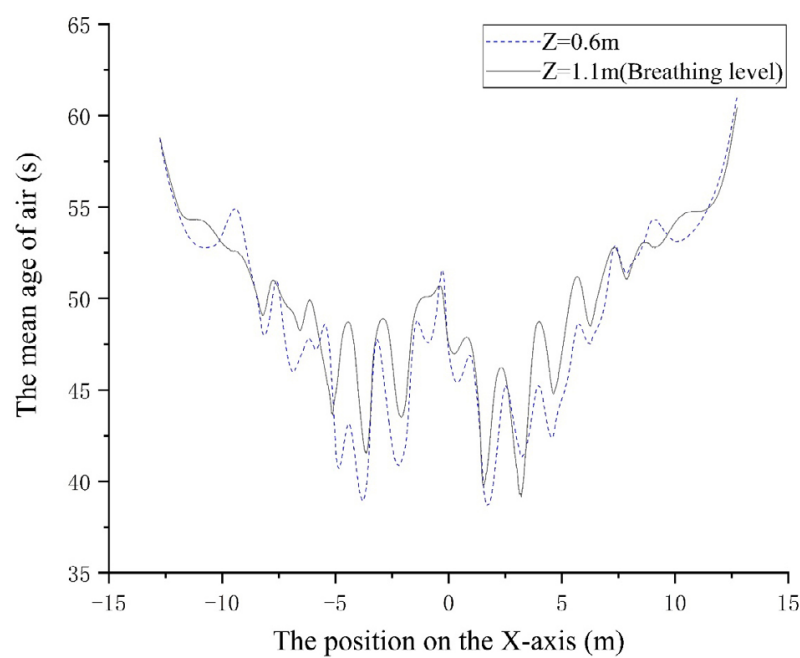

Fig. 15 Air age distribution at different heights in the length direction

\subsection{Elimination of pollutants by ventilation}

Different types of buildings require different amounts of fresh air. China National Standard and American ASHRAE Standard provide requirements and references for minimum ventilation rate of various buildings. The minimum ventilation rate of the cabin studied in this paper is about 4-5 L/(s·person). Air conditioning system ran at full load in experiment, circulating air volume is $9000 \mathrm{~m}^{3} / \mathrm{h}$, among which fresh air volume is $2000 \mathrm{~m}^{3} / \mathrm{h}$, in other words, the fresh air rate is $22.2 \%$. Figure 16 shows the variation of the average TVOC concentration in cabin with ventilation time. Average temperature and humidity of three experiments are different, varying $5.0{ }^{\circ} \mathrm{C}$ and $20.0 \%$, respectively, which led to difference in initial TVOC concentration.

Because of higher initial concentration in initial stage, elimination efficiency of pollutants was higher. With decrease of average concentration in cabin, elimination efficiency of pollutants also decreased gradually. At the same time, building materials continue to emission TVOC, and the average TVOC concentration in the vehicle may gradually reach a stable value. Guan et al. (2015) found that TVOC concentration in the cabin with the bleed air ratio of $50.0 \%$ during aircraft cruising maintained a stable value, was about $0.4 \mathrm{mg} / \mathrm{m}^{3}$. The similar elimination rate and production rate of TVOC may be the reason for the stable pollution level. It takes at least $4-6 \mathrm{~h}$ to reduce TVOC concentration to the allowable value $\left(0.6 \mathrm{mg} / \mathrm{m}^{3}\right)$ according to such ventilation method.

Due to the long-time accumulation, the in-train TVOCs concentrations keep rise to a very high level. The degree of accumulation is obviously different under different environmental conditions. Because of the air tightness of the cabin in service, concentration of TVOC is higher than the expected degree of accumulation before service. Therefore,

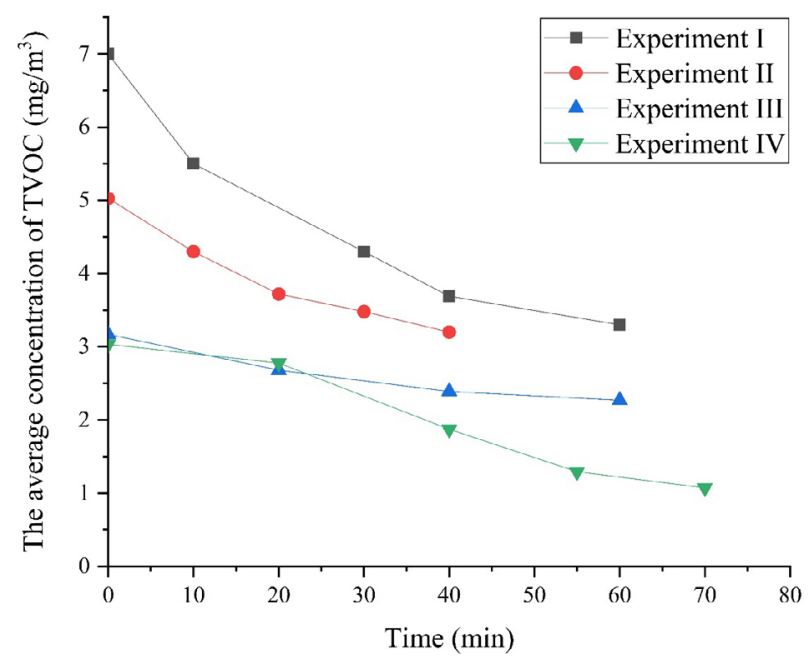

Fig. 16 The variation of average TVOC concentration in cabin with ventilation time 
it is suggested that complete displacement ventilation should be carried out for a period of time before use to eliminate pollutants completely. Figure 17 shows the simulation of TVOC concentrations over time with complete displacement ventilation to determine how this method performed in the cabin for this study. The time step is set as $0.2 \mathrm{~s}$ in our unsteady simulation. Air exchange rates $(\mathrm{ACH})$ for the two experiments are $51.4 \mathrm{~h}^{-1}, 28.6 \mathrm{~h}^{-1}$, separately. The initial TVOC pollution condition is shown in Figure 6. TVOC concentration decreases sharply during the initial stage of the displacement ventilation. The efficiency of pollutant removal gradually decreases with time, and at the same time, the concentration of TVOC gradually approaches to $0 \mathrm{mg} / \mathrm{m}^{3}$. Simulation results show that it takes about $200 \mathrm{~s}$ and $350 \mathrm{~s}$ for TVOC concentration to decrease from $2.8 \mathrm{mg} / \mathrm{m}^{3}$ to $0.05 \mathrm{mg} / \mathrm{m}^{3}$ when the complete displacement ventilation system is used. In such a time frame, new pollutants emitted from building materials is negligible. Note that the time required for a complete elimination of pollutants is longer than the maximum age of air.

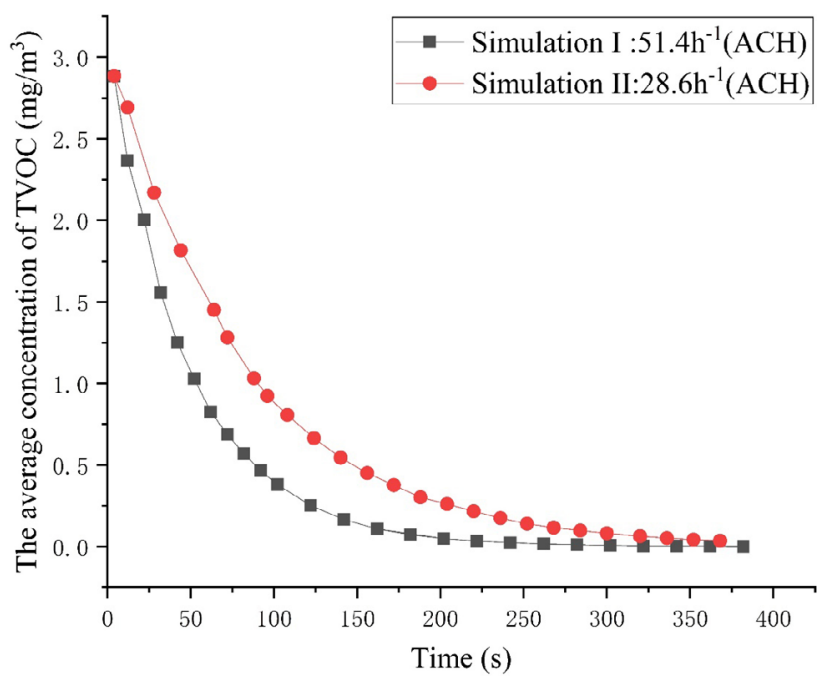

Fig. 17 TVOC concentration varies with the time of complete displacement ventilation

\section{Conclusions}

In this work, a validated CFD model was established to simulate the airflow field and the distribution of TVOC pollution in the cabin. The actual TVOC emission rates of cabin interior surfaces were used as the boundary conditions to estimate the TVOC pollution level of ordinary trains in China. For a service cycle of $12 \mathrm{~h}$, the TVOC pollution level in the cabin was more than 4 times of the Chinese IAQ Standard allowable value $\left(0.6 \mathrm{mg} / \mathrm{m}^{3}\right)$. By analyzing the rule of airflow movement, the distribution characteristics of TVOC were analyzed. The following conclusions can be drawn from this study:
1) The airflow is the main factor that affect the pollution level and distribution of TVOC in the cabin. Pollutants tend to accumulate near the seats below breathing level. Because of field in-homogeneity of the airflow, the corners of the cabin are more likely to accumulate pollutants.

2) After reducing the emission rate of tables by a third in our simulation, accumulation of pollutants at the edges of width of cabin disappears. Therefore, it is recommended to set pollutant emission source below the breathing height or reduce the intensity of emission sources near breathing area as far as possible.

3) From the edges of length of cabin to the center, the average concentration of TVOC first slowly decreases to the valley, and then increases sharply to the peak. The mean age of air changes similarly. Corresponding to the valley value, the position which is $2.5-5 \mathrm{~m}$ from the center point of cabin structure has the best air quality.

4) The mean age of air is $14-70 \mathrm{~s}$ when the air inlet velocity is $0.7 \mathrm{~m} / \mathrm{s}$. The ventilation efficiency at the breathing area is higher than that at other locations, and the mean age of air is in the range of 20-40 s. For case III, the time required for a complete dilution pollutant is $200 \mathrm{~s}$ while the maximum air age is $70 \mathrm{~s}$. To get a better indoor air quality, a ventilation system with whole fresh air should be run for 3-5 minutes before passengers boarding the cabin.

\section{Acknowledgements}

This work was supported by the Key Research and Development Program of Zhejiang Province (No. 2019C 03117).

\section{References}

Buczynska AJ, Krata A, Stranger M, et al. (2009). Atmospheric BTEXconcentrations in an area with intensive street traffic. Atmospheric Environment, 43: 311-318.

Chen X, Zhang G, Zhang Q, et al. (2011). Mass concentrations of BTEX inside air environment of buses in Changsha, China. Building and Environment, 46: 421-427.

Deng B, Kim CN (2007). CFD simulation of VOCs concentrations in a resident building with new carpet under different ventilation strategies. Building and Environment, 42: 297-303.

Desai PS, Sawant N, Keene A (2021). On COVID-19-safety ranking of seats in intercontinental commercial aircrafts: A preliminary multiphysics computational perspective. Building Simulation, 14: $1585-1596$.

Gao R, Zhang H, Li A, et al. (2021). Research on optimization and design methods for air distribution system based on target values. Building Simulation, 14: 721-735.

Gong Y, Wei Y, Cheng J, et al. (2017). Health risk assessment and personal exposure to Volatile Organic Compounds (VOCs) in metro carriages - A case study in Shanghai, China. Science of the Total Environment, 574: 1432-1438. 
Guan J, Gao K, Wang C, et al. (2014). Measurements of volatile organic compounds in aircraft cabins. Part I: Methodology and detected VOC species in 107 commercial flights. Building and Environment, 72: 154-161.

Guan J, Li Z, Yang X (2015). Net in-cabin emission rates of VOCs and contributions from outside and inside the aircraft cabin. Atmospheric Environment, 111: 1-9.

Huang H, Haghighat F (2002). Modelling of volatile organic compounds emission from dry building materials. Building and Environment, 37: $1127-1138$

Kato S, Murakami S (1988). New ventilation efficiency scales based on spatial distribution of contaminant concentration aided by numerical simulation. ASHRAE Transactions, 94(2): 309-330.

Khanchi A, Hebbern CA, Zhu J, et al. (2015). Exposure to volatile organic compounds and associated health risks in Windsor, Canada. Atmospheric Environment, 120: 152-159.

Kim KW, Lee BH, Kim S, et al. (2011). Reduction of VOC emission from natural flours filled biodegradable bio-composites for automobile interior. Journal of Hazardous Materials, 187: 37-43.

Li X, Li D, Yang X, et al. (2003). Total air age: An extension of the air age concept. Building and Environment, 38: 1263-1269.

Li T, Bai Y, Liu Z, et al. (2006). Air quality in passenger cars of the ground railway transit system in Beijing, China. Science of the Total Environment, 367: 89-95.

Li F, Liu J, Pei J, et al. (2014). Experimental study of gaseous and particulate contaminants distribution in an aircraft cabin. Atmospheric Environment, 85: 223-233.

Li J, Cao X, Liu J, et al. (2015). Global airflow field distribution in a cabin mock-up measured via large-scale 2D-PIV. Building and Environment, 93: 234-244.

Liu Z, Howard-Reed C, Cox SS, et al. (2014). Diffusion-controlled reference material for VOC emissions testing: effect of temperature and humidity. Indoor Air, 24: 283-291.

Liu A, Huang X, Yuan Z, et al. (2021). Implementing an emissionsrate model in computational fluid dynamics simulations of contaminant diffusion processes: A case study with xylene in painting workshops. Indoor and Built Environment, 30: 906-923.

Lv M, Huang W, Rong X, et al. (2020). Source apportionment of volatile organic compounds (VOCs) in vehicle cabins diffusing from interior materials. Part I: Measurements of VOCs in new cars in China. Building and Environment, 175: 106796.

Nielsen PV (2009). Control of airborne infectious diseases in ventilated spaces. Journal of the Royal Society Interface, 6: S747-S755.

Qin D, Guo B, Zhou J, et al. (2020). Indoor air formaldehyde (HCHO) pollution of urban coach cabins. Scientific Reports, 10: 332 .

Shi Z, Bai J, Han Y (2020). Distribution of ozone and its volatiles in indoor environment: a numerical simulation with CFD for the aircraft cabin. Environmental Technology, 41: 3146-3156.
Song G, Qin T, Liu H, et al. (2010). Quantitative breath analysis of volatile organic compounds of lung cancer patients. Lung Cancer, 67: 227-231.

Tong Z, Liu H (2020). Modeling in-vehicle VOCs distribution from cabin interior surfaces under solar radiation. Sustainability, 12: 5526.

Wang C, Yang X, Guan J, et al. (2014a). Source apportionment of volatile organic compounds (VOCs) in aircraft cabins. Building and Environment, 81: 1-6.

Wang H, Lin M, Chen Y (2014b). Performance evaluation of air distribution systems in three different China railway high-speed train cabins using numerical simulation. Building Simulation, 7: 629-638.

Wang H, Zheng J, Yang T, et al. (2020). Predicting the emission characteristics of VOCs in a simulated vehicle cabin environment based on small-scale chamber tests: Parameter determination and validation. Environment International, 142: 105817.

Xiong J, Yao Y, Zhang Y (2011). C-history method: Rapid measurement of the initial emittable concentration, diffusion and partition coefficients for formaldehyde and VOCs in building materials. Environmental Science \& Technology, 45: 3584-3590.

Xiong J, Wei W, Huang S, et al. (2013). Association between the emission rate and temperature for chemical pollutants in building materials: General correlation and understanding. Environmental Science \& Technology, 47: 8540-8547.

Yang L, Li M, Li X, et al. (2018). The effects of diffuser type on thermal flow and contaminant transport in high-speed train (HST) cabins-A numerical study. International Journal of Ventilation, 17: 48-62.

You K, Ge Y, Hu B, et al. (2007). Measurement of in-vehicle volatile organic compounds under static conditions. Journal of Environmental Sciences, 19: 1208-1213.

Zhang Q, Zhang G (2007). Study on TVOCs concentration distribution and evaluation of inhaled air quality under a re-circulated ventilation system. Building and Environment, 42: 1110-1118.

Zhang G, Li T, Luo M, et al. (2008). Air pollution in the microenvironment of parked new cars. Building and Environment, 43: 315-319.

Zhang Y, Xiong J, Mo J, et al. (2016). Understanding and controlling airborne organic compounds in the indoor environment: Mass transfer analysis and applications. Indoor Air, 26: 39-60.

Zhu S, Demokritou P, Spengler J (2010). Experimental and numerical investigation of micro-environmental conditions in public transportation buses. Building and Environment, 45: 2077-2088.

Zou Z, He J, Yang X (2020). An experimental method for measuring VOC emissions from individual human whole-body skin under controlled conditions. Building and Environment, 181: 107137. 